\title{
A REVIEW OF THE SEROLOGICAL RESULTS OF THE TREATMENT OF SYPHILIS IN THE NOTTINGHAM CLINIC
}

\section{ADDENDUM}

Comparison With the Results ObTained BY THE Alternating Continuous System of Syphilitic THERAPY

IT would not be profitable to consider in detail the numerous reports on the results of alternating continuous syphilitic therapy since these are in general agreement and, for my purpose, are largely replaced by the complete and elaborate studies of the Co-operative Clinical Group and of the Health Organisation of the League of Nations.

The Co-operative Clinical Group of the United States ${ }^{1}$ combined the material from five large syphilis clinics and studied the results of regular and irregular treatment. The material consisted of 3,244 patients with syphilis who had been followed for six months or longer. The practice of the clinics concerned leaned largely towards the use of arsphenamine, but $35^{\circ}$ cases were collected in which neo-arsphenamine had been the drug employed. The following definitions were accepted for the purposes of comparison. " "Continuous" treatment is uninterrupted treatment with an arsphenamine or a heavy metal, or both, whether administered in alternation or simultaneously, throughout treatment, including socalled " overlapping " treatment. The distinctive feature of this scheme is its uninterrupted character.

"Intermittent" treatment is treatment with an arsphenamine or heavy metal, or both, which is interrupted by short rest intervals throughout treatment, whether they are purposeful or not. The distinctive feature is the rest interval of one month or more duration.

The standard course ${ }^{3}$ consisted of $12.95 \mathrm{gm}$. " 606 " or approximately $2 \mathrm{I} \cdot 0 \mathrm{gm}$. " $9 \mathrm{I} 4$ " and $7.6 \mathrm{gm}$. bismuth in sixty-nine weeks, and the findings in the group which 


\section{TREATMENT OF SYPHILIS}

followed this course may be epitomised as follows. A group of 2,889 cases comprising sero-negative primary, sero-positive primary, secondary (first year) and secondary (manifestations after the first year), is considered for the purpose of comparing the results of continuous, intermittent, intensive and irregular treatment. ${ }^{4}$ The cases had been treated with arsphenamine or neoarsphenamine exclusively, or predominantly, as the arsenical. Of the total, 474 received continuous, and I,560 intermittent treatment. Satisfactory results (excluding reinfection) were obtained in 33 per cent. of continuously treated cases and $2 \mathrm{I}$ per cent. of intermittently treated cases. Relapses occurred in 26.6 per cent. of the $2,88 \mathrm{~g}$ cases. Of these, I3.I per cent. occurred under continuous treatment and 20.7 per cent. under intermittent treatment.

The effect of the various schemes of treatment upon the rate of reversal of the blood Wassermann reaction was also examined in the same group of cases. Whereas $52 \cdot 6$ per cent. of the cases continuously treated became Wassermann negative in three months or under, only 3.8 per cent. of the intermittently treated did likewise. Again, 29.2 per cent. of continuously treated cases took four to twelve months to become Wassermann negative against 33.5 per cent. intermittently treated. Over two and a half years' treatment was required to reduce to negativity a stubborn 4 per cent. intermittently treated cases, as against $\mathrm{I} \cdot 5$ per cent. under the continuous plan.

Studied from another angle it was found that in this group the proportion of patients whose blood Wassermann reaction failed to become permanently negative during the period of treatment or observation was $6 \cdot 2$ per cent. under continuous treatment and 17.5 per cent. under intermittent treatment.

In cases of "delayed reversal" of the Wassermann reaction the difference between the two schemes of treatment was striking, intermittent treatment giving rise to four times as many delayed reversals (I9.8 versus 5 per cent.) as continuous. In the case of serological relapse (this included only patients whose serological relapse was the last observed fact, not merely patients who relapsed and again became negative during treatment) the same relative proportions of effectiveness prevailed. 
All the 2,889 cases on which these comparisons are based received " 606 " or " $9 I_{4}$ " exclusively or predominantly as the arsenical to the time of the permanent reversal of the blood Wassermann reaction regardless of treatment received thereafter, the scheme of treatment being based on the same time period. ${ }^{5}$

Moore, ${ }^{6}$ in his book, "The Modern Treatment of Syphilis," has studied the same material as the Cooperative Clinical Group and presents the same conclusions, which will therefore not be repeated. His definition of intermittent treatment, however, is of interest. Intermittent treatment consisted of " one or more courses of arsphenamine, followed or not by a heavy metal, but always with an involuntary (from our standpoint) rest period without treatment before the subsequent arsphenamine course."

In another publication based on the same material by Stokes et alii ${ }^{7}$ a comparison is made between cases of early syphilis treated or observed for two years or more, according to the system of treatment. "Satisfactory" results were apportioned in percentages as follows :-

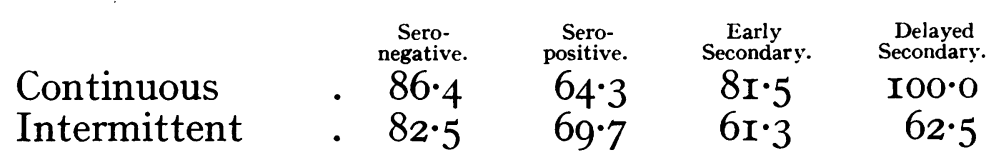

The details of the intermittent course are not given.

In considering the results claimed by the American authors for the intermittent system of treatment one is immediately struck by the definition of the system. The essential they insist upon is the rest period of one month or more duration. Arsphenamine (or neo-arsphenamine) is always given, but a heavy metal need not be given concurrently. Moore may give a heavy metal only, after the first course. Where the intermittent system is followed in this country and in Europe the simultaneous administration of arsenic and a heavy metal is commonly favoured. Strictly speaking, these clinics use the " simultaneous intermittent" system, and not the more elastic "intermittent" system.

It may be granted at once that the Co-operative Clinical Group has brought forward overwhelming evidence of the superiority of the continuous as opposed to the intermittent system of therapy, but the evidence 
cannot be taken as applying to the simultaneous intermittent system also. For this reason the results of intermittent treatment given above need not be considered here as they are not strictly germane to the discussion, except for one interesting point. In the Table taken from Stokes' comparison of satisfactory results it will be noticed that the intermittent system gives a solitary superiority of result for the sero-positive primary cases, i.e., 69.7 per cent. as against 64.3 per cent. It is suggested that " the rests permit the adding of some increments of constitutional reaction and resistance to the effects of treatment." In secondary cases no increment of resistance is necessary, so the intermittent results are poor. If this explanation is correct it forms an argument for favouring rests during the treatment of sero-positive primary cases at least.

Whatever we may think of the efficacy of the intermittent system as portrayed above, there is no doubt that the continuous system advocated by the Co-operative Clinical Group represents the highest development yet attained, and the results rank among the best, for that method. Let us consider two points where a comparison may be attempted. In reviewing the rate of the reversal of the blood Wassermann reaction it was stated that 52.6 per cent. of the cases continuously treated became Wassermann negative in three months or under, and a further $29^{\circ} 2$ per cent. in four to twelve months. In the simultaneous intermittent system as practised at St. Thomas's Hospital and the Nottingham Clinic the Wassermann test following the rest after the first course is taken at approximately four months after the beginning of treatment. The second test is taken at approximately eight months after the beginning of treatment. The sero-positive primary and secondary cases shown in Table B Combined, total 440. Of these, 83 gave Wassermann reactions other than negative after the first course, and a further 32 relapsed serologically at a later date, giving II 5 cases which were not permanently negative four months from the commencement of treatment. Fifty-five patients did not attend after the first course and 29 were not observed over six months following the first course. If these are subtracted it leaves $35^{6}$ sero-positive primary and early secondary cases, of whom II5 were not permanently negative; in other words, 


\section{BRITISH JOURNAL OF VENEREAL DISEASES}

$67 \cdot 7$ per cent. were permanently Wassermann negative after the first course.

Similarly, by subtracting the 29 sero-positive primary and early secondary cases which were only observed for six to nine months after the first course, we are left with I54 cases, of which 32 were not Wassermann negative after the second course or which relapsed later. That is, 79.23 per cent. were permanently negative after eight months' treatment.

These results are not strictly comparable, as the American statistics included late secondary cases (manifestations after the first year). On the other hand, their results are based on a period up to one year's treatment against the eight months of the St. Thomas's Hospital and Nottingham series. On the whole, it does not seem to me that either system can claim superiority on this head.

The second point where a comparison may be made is in a study of the proportion of patients whose blood Wassermann reaction failed to become permanently negative during the period of treatment or observation. This amounted to $6 \cdot 2$ per cent. under continuous treatment.

From Table F Combined we see that 2 I9 patients in the sero-positive primary and early secondary stages were observed for six months or longer following suspension of treatment and of these 13 gave positive Wassermann reactions. That is, $5^{\circ} 94$ per cent. failed to become permanently negative under simultaneous intermittent treatment; a figure slightly better than that for continuous treatment and much better than the I7.5 per cent. quoted for " intermittent" treatment.

Let us now turn to the latest large scale inquiry into the treatment of syphilis, carried out by the Health Organisation of the League of Nations. ${ }^{8}$ Five countries took part and 25,623 case cards were examined. "Basic treatment," that is, treatment of average intensity was taken for the continuously treated cases to comprise I2 gm. of " $9 \mathrm{I} 4$ " and $4 \mathrm{gm}$. metallic bismuth over a period of sixty-five weeks. No lapse exceeding four weeks between injections was allowed and lapses of such length must be exceptional. The " basic treatment" under the intermittent system was taken as $4 \mathrm{gm}$. of " $9 \mathrm{I} 4$ " and $0.8 \mathrm{gm}$. metallic bismuth in each course. Sero-negative primary syphilis must receive two such courses spread 


\section{TREATMENT OF SYPHILIS}

over a period of thirty weeks. Sero-positive primary and secondary syphilis must receive five such courses over a period of twenty-one months. Treatment must be continued in any case for twelve months after the last positive clinical or serological findings. An illuminating comparative Table is quoted below.

S. I.-Sero-negative primary syphilis.

S. I or S. 2.-Sero-negative or sero-positive primary syphilis, i.e., Sp. pallida present but serological reaction not performed at the beginning.

S. 2.-Sero-positive primary syphilis.

S. 3.-Secondary syphilis in the first year of the infection.

S. 3 or S. 4.-Secondary syphilis, date of infection unknown.

S. 4.-Secondary syphilis, after the first year of infection.

In the sero-negative primary (S. I) group, Denmark gave the best result with $97 \cdot 49$ per cent. of cases remaining serologically negative under intermittent treatment. The best result for continuous treatment was obtained by the United States with 90.36 per cent. cases remaining negative. The remaining two groups of continuously treated cases are too small to be taken into consideration. The other groups of cases treated intermittently are approximately 7,8 and 9 per cent. behind the figure for continuous therapy, with one (France) over I2 per cent. behind. At its best the intermittent system gave the best results in sero-negative primary cases.

The components of Group "S. I or S. 2 " cannot be compared owing to the paucity of numbers for the continuously treated cases.

Intermittent treatment in Denmark renders $9 \mathrm{I} \cdot 06$ per cent. of sero-positive primary cases serologically negative. Other countries give figures I6, I6 and 21 per cent. lower and the United States drops to $6 \mathrm{I} \cdot 70$ per cent. negative results. The continuously treated cases centred round $82 \cdot 0$ per cent. negatives, if we except the very small group from France. The early secondary cases treated intermittently gave the best results again in Denmark with $84 . \mathrm{I} 7$ per cent. negative, decreasing through the other countries to the United States with $57 \cdot 8$ per cent. 
BRITISH JOURNAL OF VENEREAL DISEASES

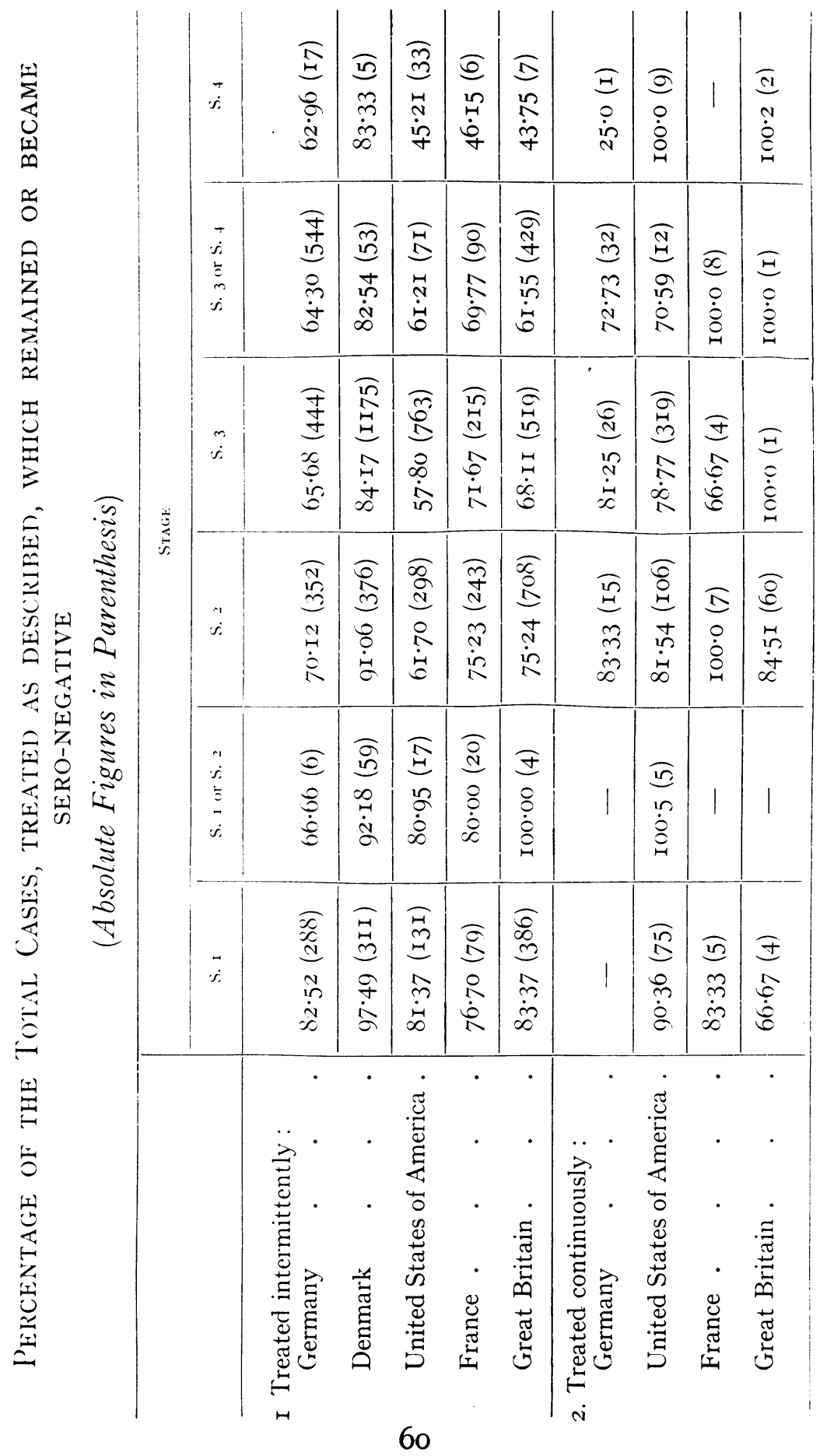

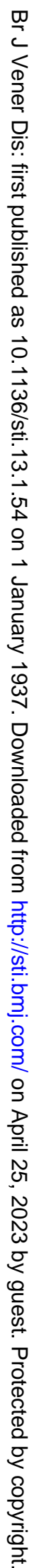




\section{TREATMENT OF SYPHILIS}

The continuous system gave $8 \mathrm{I} \cdot 25$ and $78 \cdot 77$ per cent. negative results (missing the two small groups).

The numbers are too small to be of use for comparison in the class for secondary syphilis after the first year of the infection. The Report points out that one may argue that factors such as frequency of serological tests, method of test and so on might influence the general results. No such factors can operate in the case of clinical relapse. The percentage of clinical relapse noted in the United States cases is :-

Continuous treatment . . . . . 0.77

Intermittent treatment $\quad . \quad$. 9.75

Partly continuous, partly intermittent . II.66

The cases treated continuously in Germany, France and the United Kingdom, though less numerous (about 200 in all) also yielded very satisfactory results, the percentage of clinical relapses amounting only to 0.82 , whereas the corresponding percentage for intermittently treated cases in all countries still stands at 5.66 . The United Kingdom relapse percentage for intermittently treated cases is $2 \cdot 49$ as against Denmark's $3 \cdot 36$. Through all the Tables given in the Report the same comparative values run. The best results with intermittent treatment are obtained in Denmark, followed by the United Kingdom. It is stated in the Report that particularly satisfactory results were also obtained in a number of clinics in the other countries, and when the methods which they used were compared, they were found to agree in striking fashion with those applied in Denmark and the United Kingdom, but generally the continuous system gave better results.

The same point arises here as when considering the American statistics. The quantity of drugs administered under the basic treatment for the intermittent system (4 gm. " $9 \mathrm{I} 4$ " and $0.8 \mathrm{gm}$. metallic bismuth in fifteen weeks) does not approach the quantity given at St. Thomas's Hospital or the Nottingham Clinic or, for that matter, any other clinic I have visited in Britain. It is understood that many of the clinics participating in the inquiry must have given more arsenic and bismuth than that laid down in the basic treatment, but that many did not is shown by its definition as "treatment of average intensity." 


\section{BRITISH JOURNAL OF VENEREAL DISEASES}

The St. Thomas's Hospital and Nottingham data as shown in Table $\mathrm{F}$ Combined give the following percentages of the total cases which remained or became sero-negative : 99.3I for sero-negative primary syphilis, 94.83 for sero-positive primary syphilis and $93 \cdot 2$ for early secondary syphilis (corresponding to Group S. 3 in the table above). These results are better than those obtained by either system in the League Report.

It is important to remember that the continuously treated cases in the League Report represent in some respects a homogeneous group (longer prescribed minimum period of treatment, cases collected from a comparatively small number of clinics) so that the results may be looked upon as the best obtainable by that system. The intermittently treated cases were collected from a large number of clinics with varying schemes of treatment and are far from representing, in my opinion, the best results possible. In view of the results obtained at the St. Thomas's Hospital and Nottingham Clinics and given in detail above it is suggested that there is no indication that the use of simultaneous intermittent treatment, if given in sufficient dosage, should be abandoned in favour of continuous treatment.

This article consists of abstracts from a Thesis accepted for the M.D. degree of the University of Edinburgh.

\section{REFERENCES}

(I) Stokes, J. H., et alii. Ven. Dis. Inf., I932, 13, I65.

(2) STOKEs, J. H., et alii. Ven. Dis. Inf., 1932, 13, 209.

(3) Moore, J. E. " The Modern Treatment of Syphilis," London, I933, p. 201.

(4) Stokes, J. H., et alii. Ven. Dis Inf., I932, 13, 217.

(5) Stokes, J. H., et alii. Ven. Dis Inf., I932, 13, 279.

(6) Moore, J. E. " The Modern Treatment of Syphilis," London, I933, p. I90.

(7) Stokes, J. H., et alii. Amer. Jour. Med. Sci., I934, 188, 662.

(8) Martenstein, H. Quart. Bull. of the Health Organisation, I935, 4. 129 . 